\title{
Surface Relief Profile of Photopolymerisable Systems in a Single Illuminated Spot
}

Tsvetanka Babeva

Bulgarian Academy of Sciences

Dana Mackey

Technological University Dublin, dana.mackey@tudublin.ie

Izabela Naydenova

Technological University Dublin, izabela.naydenova@tudublin.ie

See next page for additional authors

Follow this and additional works at: https://arrow.tudublin.ie/cieocon2

Part of the Condensed Matter Physics Commons

\section{Recommended Citation}

Babeva, T., Mackey, D. \& Naydenova, I. (2009). Surface relief profile of photopolymerisable systems in a single Illuminated spot. International Commission for Optics Topical meeting on Emerging trends and novel materials in photonics, vol.1288, pg. 43-46. doi:10.1063/1.3521367

This Conference Paper is brought to you for free and open access by the Centre for Industrial and Engineering Optics at ARROW@TU Dublin. It has been accepted for inclusion in Conference Papers by an authorized administrator of ARROW@TU Dublin. For more information, please contact arrow.admin@tudublin.ie, aisling.coyne@tudublin.ie,gerard.connolly@tudublin.ie. 


\section{Authors}

Tsvetanka Babeva, Dana Mackey, Izabela Naydenova, Suzanne Martin, and Vincent Toal 
2009-01-01

\section{Surface Relief Profile of Photopolymerisable Systems in a Single Illuminated Spot}

Tsvetanka Babeva

Bulgarian Academy of Sciences

Dana Mackey

Dublin Institute of Technology

Izabela Naydenova

Dublin Institute of Technology, izabela.naydenova@dit.ie

Suzanne Martin

Dublin Institute of Technology, suzanne.martin@dit.ie

Vincent Toal

Dublin Institute of Technology

\section{Recommended Citation}

Babeva, T., Mackey, D., Naydenova, I., Martin, S., Toal, V.: Surface relief profile of photopolymerisable systems in a single Illuminated spot. Conference proceedings of the International Commission for Optics Topical meeting on Emerging trends and novel materials in photonics, v.1288, 43-46, 2009. 
1-1-2009

\section{Surface Relief Profile of Photopolymerisable Systems in a Single Illuminated Spot}

Tsvetanka Babeva

Bulgarian Academy of Sciences

Dana Mackey

Dublin Institute of Technology

Izabela Naydenova

Centre for Industrial and Engineering Optics, Dublin Institute of Technology, izabela.naydenova@dit.ie

Suzanne Martin

Centre for Industrial and Engineering Optics, Dublin Institute of Technology

Vincent Toal

Centre for Industrial and Engineering Optics, Dublin Institute of Technology 


\title{
Surface Relief Profile of Photopolymerisable Systems in a Single Illuminated Spot
}

\author{
T. Babeva ${ }^{\mathrm{a}, \mathrm{b}}$, D. Mackey ${ }^{\mathrm{c}}$, I. Naydenova ${ }^{\mathrm{a}}, \mathrm{S}$. Martin $^{\mathrm{a}}$ and V. Toal ${ }^{\mathrm{a}}$ \\ ${ }^{a}$ Centre for Industrial and Engineering Optics, School of Physics, Dublin Institute of Technology, \\ Kevin Street, Dublin 8, Ireland \\ ${ }^{b}$ Central Laboratory of Photoprocesses, Bulgarian Academy of Sciences, \\ Acad. G. Bonchev Street, Bl. 109, 1113 Sofia, Bulgaria \\ ${ }^{c}$ School of Mathematical Sciences, Dublin Institute of Technology, Kevin Street, Dublin 8, Ireland
}

\begin{abstract}
The formation of surface relief profile in photopolymerisable systems when illuminated with a focused beam of light is simulated numerically using a two-way diffusion model that accounts both for monomer and short polymer chains diffusion. The concentration and spatial distribution dynamics of monomer, short and long polymer chains are calculated. It is assumed that the surface profile is a linear combination of monomer and polymer concentration with appropriate coefficients accounting for polymer shrinkage. A good agreement between the calculated and the experimentally measured profiles is observed thus demonstrating the successful application of the two way diffusion in modeling this system.
\end{abstract}

Keywords: : Photopolymer, diffusion, surface relief profile, two-way diffusion model

PACS: 07.05.Tp, 42.40.My, 42.70.Km, 42.70.Ln, 81.05.Mh

\section{INTRODUCTION}

The interest in photopolymer systems has remarkably increased in the past few years. The photopolymer materials have reached primary positions in many areas as holography, manufacturing of optical elements, optical interconnections, holographic data storage etc [1].

Acrylamide based photopolymer systems have been primarily developed as high sensitivity self processing photosensitive materials for volume holography [2]. In addition to the photoinduced volume refractive index changes when an acrylamide-based photopolymer surface is exposed to a patterned light of appropriate wavelength a post-exposure swelling in the illuminated area is observed following the initial shrinkage due to the polymerization. The swelling is observed routinely in gratings recorded in acrylamide-based photopolymer and has been experimentally investigated elsewhere [3-5]. The real time observation of the evolution of surface relief profile conducted in our previous study [6] showed that two processes are clearly distinguishable: rapid increase of profile height followed by a slower decrease. We have demonstrated that the surface profile dynamics is directly connected with diffusion processes occurring in the photopolymerisable system [6] and thus the post-exposure evolution of the surface relief profile in a single illuminated spot can be used for calculation of monomer and polymer diffusion coefficients in photopolymerisable materials. To explore further the origin of the surface relief profile formation it will be a clear advantage to develop a model for its numerical simulation. Recently, we have proposed a two-way diffusion model for formation of short exposure gratings in acrylamide-based photopolymer [7,8]. The model accounts for diffusion of both monomer and polymer molecules and distinguishes between short-chain polymers capable of diffusing and long-chain polymers that are immobile [7,8].

In this paper we have modified the two-way diffusion model in order to simulate numerically the surface relief formation in a single illuminated spot. The temporal dynamics of the spatial distribution of monomer and polymer concentrations in a single illuminated spot are calculated and the calculated profiles are compared with the experimental results. 


\section{RESULTS AND DISCUSSION}

The investigations were performed using a photopolymer system, developed in the Centre for Industrial and Engineering Optics, Dublin Institute of Technology [9], which consists of $17.5 \mathrm{ml}$ stock solution of polyvinyl alcohol $(10 \mathrm{w} / \mathrm{w} \%), 2 \mathrm{ml}$ triethanolamine, $0.6 \mathrm{~g}$ acrylamide, $0.2 \mathrm{~g} \mathrm{~N}, \mathrm{~N}$-methylene bisacrylamide and $4 \mathrm{ml}$ Erythrosin B dye stock solution of concentration $1.1 \mathrm{mM}$. An amount of $0.4 \mathrm{ml}$ of the well mixed solution was gravity settled on a levelled $2.5 \mathrm{~cm} \times 7.5 \mathrm{~cm}$ single glass substrate, so the upper surface of the layer was open to the air. The thickness of the layers after drying for $24 \mathrm{~h}$ in darkness under normal laboratory conditions $\left(\mathrm{T}^{\mathrm{o}}=21-23^{\circ} \mathrm{C}\right.$ and $40-60 \%$ relative humidity) was $35 \pm 2 \mu \mathrm{m}$.

The illumination of the samples and collection of the surface profiles were performed by White Light Interferometric (WLI) surface profiler MicroXAM S/N 8038. The built-in diaphragm of the WLI profiler (1mm in diameter, positioned $220 \mathrm{~mm}$ from the sample) was imaged onto the sample surface for $30 \mathrm{~s}$ using light of wavelength $554 \mathrm{~nm}$ and controlled intensity resulting in an approximately circular spot $55 \mu \mathrm{m}$ in diameter. Immediately following the exposure the images of the sample surface were collected in dark. The advantage of single spot illumination is that one can monitor in real time the dynamic of the surface profile by taking images at different times using WLI profiler. More details concerning sample preparation, illumination and image collection can be found elsewhere [6].

(a)

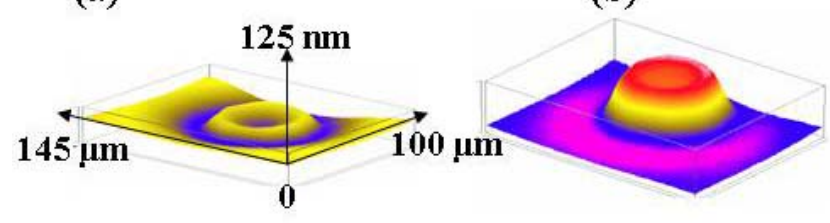

(c)

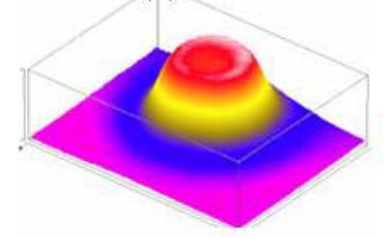

(d)

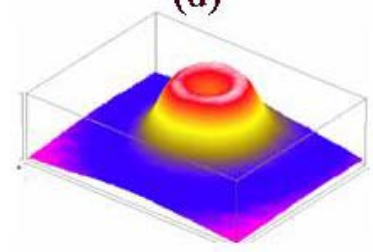

FIGURE 1. Surface relief profiles for single spot illumination of $30 \mathrm{~s} \mathrm{(a)} \mathrm{and} \mathrm{collected} 15 \mathrm{~s}$ (b), $45 \mathrm{~s} \mathrm{(c)} \mathrm{and} 300 \mathrm{~s}$ (d) after exposure by WLI profiler

Figure 1 presents the surface profiles after single spot illumination for $30 \mathrm{~s}$ and those collected in the dark $15 \mathrm{~s}$, $45 \mathrm{~s}$ and $300 \mathrm{~s}$ after the illumination was turned off. It can be seen that exposure causes initial shrinkage followed by the increase of the profile high. The photopolymerization visualized by the shrinkage (Fig. 1a) leads to the consumption of monomer in the illuminated spot. Due to the established concentration gradient monomer diffuses toward illuminated area and the profile grows. Even after exposure the gradient continues to drive monomer diffusion and the surface relief profile continues to grow (Fig.1 b,c). After some time, depending on the conditions of the initial illumination, a decrease in profile height is detected. Similar processes (giving rise to an initial increase followed by a decrease in diffraction efficiency) were observed in the post-exposure dynamics of the holographic gratings recorded with short exposure times [7,10,11]. The processes were distinguished as monomer and short polymer chain diffusion processes in opposite directions [7,11]. Therefore here we assumed that the profile decrease is due to diffusion of short polymer chains away from the illuminated area. To verify these assumptions we used the reported in [8] two-way diffusion model. Because of the radial symmetry we can assume that the movement of monomer is mainly in the radial direction and that the contribution of non-radial monomer movement is negligible. Further, we have shown [6] that the appropriate choice of the thickness of the studied layers ensures negligible contribution from the depth, so the monomer movement is mainly in lateral direction. Therefore we can approximate our case to one-dimensional case and apply 1D diffusion equations. The model equations are:

$$
\begin{aligned}
& \frac{\partial m}{\partial t}=D_{m} \frac{\partial^{2} m}{\partial x^{2}}-\Phi(t) F(x) m \\
& \frac{\partial p_{1}}{\partial t}=\frac{\partial}{\partial x}\left[D_{p}(x) \frac{\partial p_{1}}{\partial x}\right]+\Phi(t)\left(F(x) m-\Gamma m p_{1}\right), \\
& \frac{\partial p_{2}}{\partial t}=\Phi(t) \Gamma m p_{1} .
\end{aligned}
$$

where $m, p_{1}$ and $p_{2}$ are the concentrations of monomer and short and long polymer chains, $D_{m}$ and $D_{p}(\mathrm{x})$ are monomer and polymer diffusion coefficients, $\Phi(t)=1$ for $t<t_{\mathrm{e}}$, and $\Phi(t)=0$ for $t>t_{\mathrm{e}}, t_{\mathrm{e}}$ being the exposure time, $\Gamma$ is the 
rate of conversion from short to long chains, and $F(x)$ is the polymerization rate, $t$ and $x$ are time and spatial coordinates. $D_{p}(\mathrm{x})$ and $F(\mathrm{x})$ are proportional to the illumination pattern intensity that is given by $f(x)=\exp \left(-(x-L)^{2} / a\right)$, where $2 L=145 \mu \mathrm{m}$, and $a$ is a constant equal to 0.04 for the simulation presented.

The first equation concerns the changes of monomer concentration with time that are due to diffusion and polymerization. The main difference of our model compared to existing models $[12,13]$ is that the model accounts for polymer diffusion away from the bright fringes and distinguishes between two types of polymer molecules: short polymers $p_{1}$ that are mobile and are capable of diffusing and immobile polymers $p_{2}$ that are crosslinked or too long to move.. Second equation shows that the concentration of short polymers changes due to polymerization, diffusion and conversion immobile polymers. The concentration of long polymer (third equation) is proportional to polymer and monomer concentrations. After exposure the long polymer concentration is constant. More details about nondimensionalising the system of equations, initial and boundary conditions and numerical integration can be found elsewhere [8].

Figure 2 presents the calculated concentration profiles using the two-way diffusion model. The model parameters as polymerization rate and diffusion coefficients are taken from previous studies [7, 14]. The initial monomer concentration is unit. It is seen that $m$ decreases to zero in the illuminated spot center due to the consumption of monomer in the illuminated area because of the photopolymerization (Fig. 1 (a)). As mentioned, this sets up a concentration gradient and monomer starts to diffuse from the unexposed to the exposed area leading to an increase of monomer concentration in the centre of the spot. Due to the photopolymerization the concentrations of short (mobile) (Fig. 1 (b)) and long/crosslinked (immobile) (Fig. 1 (c)) polymer molecules increase during illumination (see solid and dashed lines that refers to time of 0.3 and 3 seconds). When the light is turned off ( $t=30 \mathrm{~s})$ no more polymer molecules are generated, hence no changes in polymer concentration are expected. However it can be seen that in the centre of the spot the short polymer concentration decreases (the change is very small on this time scale because the process is very slow). The reason is that short polymers are mobile and can diffuse away from the illuminated area. On the other hand the spatial distribution of the concentration of long/crosslinked polymers does not change after illumination because they are incapable of diffusing.
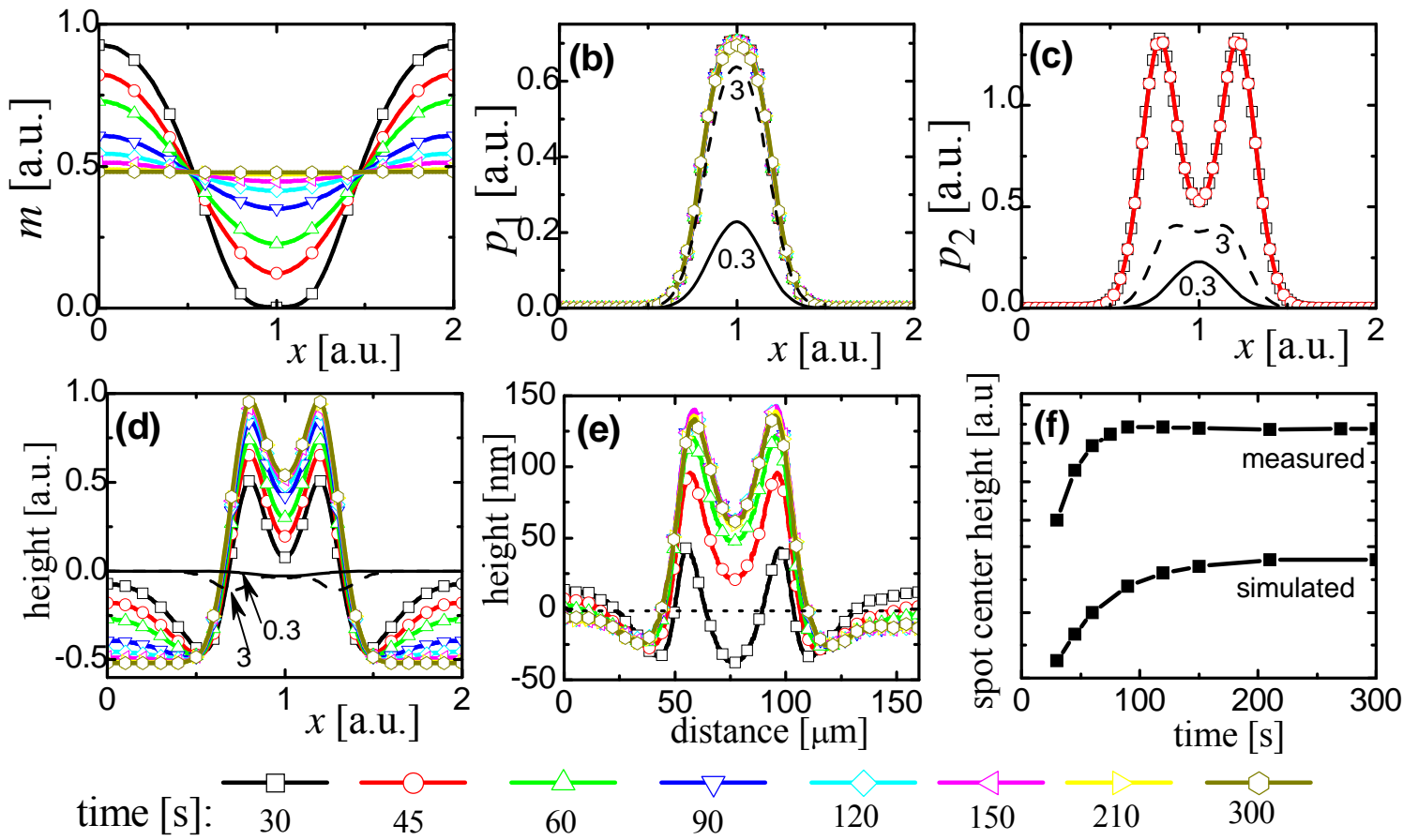

FIGURE 2. Calculated concentration profiles of monomer (a), short (b) and long (c) polymer chains; Numerically calculated (d) and experimentally measured (e) cross-sections of the surface relief profile and post-exposure dynamics of the profile centre (f); $(t=30 \mathrm{~s}$ is the end of exposure); the horizontal dot line denotes the polymer surface, the dash and solid lines are the profiles for exposure of $0.3 \mathrm{~s}$ and $3 \mathrm{~s}$.

We assume that the surface relief profile is proportional to the concentration profiles of monomer and polymer molecules. Fig. 1 (d) shows the linear combination of the profiles with coefficients of 1 and 0.87 for monomer and polymer, respectively. In this way polymer shrinkage of $13 \%$ is assumed. Fig 1 (e) and (f) present the 
experimentally measured post-exposure cross sections of surface profile and measured and simulated temporal dynamics of spot center height. It is worth noting the good agreement between the calculated (d) and measured (e) surface relief profiles, as well as the dynamics of the spot centre height (f).

In conclusion, the two-way diffusion model originally developed to account for holographic grating formation under short exposure conditions $[7,8]$ has here been successfully applied to study of the formation of surface relief in photopolymerisable systems in a single illuminated spot. The model can also be applied to surface relief grating formation in acrylamide-based photopolymer. It can also assist the design of HOE's.

\section{ACKNOWLEDGMENTS}

The financial support of Science Foundation Ireland (grant No 065/RFP/PHY085) and COST Action MP0604 is highly appreciated. The authors would like to acknowledge the School of Physics at DIT and FOCAS, DIT, for technical support. T. Babeva would like to thank the Arnold F Graves Postdoctoral programme at DIT

\section{REFERENCES}

1. T. J. Trout, J. J. Schmieg, W. Y. Gambogi, and A. M. Weber, Adv. Mater. 10, 1219-1224 (1998).

2. S. Calixto, Appl. Opt. 26, 3904-3910 (1987)

3. I. Naydenova, E. Mihaylova, S. Martin and V. Toal, Opt. Express 13, 4878- 4889 (2005).

4. K. Pavani, I. Naydenova, S. Martin and V. Toal, J. Opt. A: Pure Appl. Opt. 9, 43 - 48 (2007).

5. S. Gallego, A. Márquez, S. Marini, E. Fernández, M. Ortuño and I. Pascual, Opt. Express 17, 18279 - 18291 (2009).

6. Tz. Babeva, I. Naydenova, S. Martin and V. Toal, Opt. Express, 16, 8487 - 8497 (2008).

7. I. Naydenova, R. Jallapuram, R. Howard, S. Martin and V. Toal, Appl. Opt. 43, 2900 - 2905 (2004).

8. T. Babeva, I. Naydenova, D. Mackey, S. Martin and V. Toal, JOSA B 27, 197 - 203 (2010).

9. S. Martin, C. A. Feely and V. Toal, Appl. Opt. 36, 5757 - 5768 (1997).

10. V. L. Colvin, R. G. Larson, A. L. Harris and M. L. Schilling, J. Appl. Phys. 81, 5913 - 5923 (1997).

11. A. Havranek, M. Kveton, and J. Havrankova, Polymer Bulletin 58, 261 - 269 (2007).

12. J. T. Sheridan and J. R. Lawrence, J. Opt. Soc. Am. A 17, 1108 - 1114 (2000).

13. J. T. Sheridan, M. Downey and F. T. O’Neill, J. Opt. A: Pure and Appl. Opt. 3, 477 - 488 (2001).

14. R. Jallapuram, I. Naydenova, H. J. Byrne, S. Martin, R. Howard and V. Toal, Appl. Opt. 47, 206 - 212 (2008). 